\title{
Management of Incidental Left-Side Gallbladder in Laparoscopic Cholecystectomy
}

\author{
Vincenzo Leone $\mathrm{a}^{\mathrm{a}, \mathrm{b}}$, Nico Console ${ }^{\mathrm{a}}$
}

\begin{abstract}
The left-sided gallbladder without situs inversus viscerum is rare biliary anomaly with a prevalence of $0.2 \%$. Because of routine preoperative studies may fail to identify it, surgeons encountering incidental left-sided gallbladder should be aware of the possibility of associated biliary and vascular anomalies. In such case we recommend to modify the standardized surgical techniques particularly in the preparation of the elements of Calot's triangle to avoid iatrogenic injuries.
\end{abstract}

Keywords: Left-sided gallbladder; Situs inversus; Laparoscopy; Sinistroposition

\section{Introduction}

Ectopic gallbladders represent cases where a full formed gallbladder lies in an abnormal site. Normally, the gallbladder is located on the visceral surface of the liver, just on the line of the middle hepatic vein (van Rex-Cantlie line) and between the right anterior and left medial segments [1]. The left-sided gallbladder (LSG) without situs inversus viscerum is rare biliary anomaly with a prevalence of $0.2 \%$ and was described for the first time in 1886 by Hochstetter [2]. It may occur either as a single anomaly or in association with one or more congenital abnormalities: portal vein anomalies, biliary system anomalies, segment IV atrophy, complete or partial situs inversus viscerum. As routine preoperative studies may not detect this anomaly, it may provide the surgeons with an unusual surprise during laparoscopy and when discovered

Manuscript accepted for publication May 13, 2013

\footnotetext{
a Department of General Surgery, St. Maria Nuova Hospital, Piazza St. Maria Nuova, 150122 Firenze, Italy

${ }^{b}$ Corresponding author: Vincenzo Leone, via Monteverdi n 85/b, 50144

Firenze, Italy. Email: vinc leone@tin.it
}

doi: http://dx.doi.org/10.4021/jcs178w must be promptly recognized to find an unpredictable confluence of the cystic duct in the common bile duct (CBD).

\section{Case Report}

A 37-year-old woman presented with a 2-month history of colicky epigastric pain that had become progressively worse and radiated to her back and right flank. There was no fever or jaundice. Clinical examination was unremarkable apart from an increased body mass index. A full blood count and liver function tests were normal. An abdominal ultrasound scan showed two stones in the gallbladder with a diameter of $2-2.5 \mathrm{~cm}$ without evidence of acute cholecystitis.

A laparoscopic cholecystectomy was performed. At operation $10 \mathrm{~mm}$ umbilical camera port was inserted using Hasson technique. Under direct vision three other working ports was inserted: the first one $5 \mathrm{~mm}$ port below the xiphoid process, the second one $10 \mathrm{~mm}$ port on the left midclavicular line about $10 \mathrm{~cm}$ below the rib margin and the third one 5 $\mathrm{mm}$ port on the patient's right lower flank. The surgeon was between patient's spread legs and the assistant was on patient's left side according standard technique [3]. We found the gallbladder attached to the inferior surface of segment 3 and to the left of a well-formed falciform ligament (Fig. 1). No situs inversus was present and the other abdominal organs were normally positioned. An extra $5 \mathrm{~mm}$ port was placed on the right subcostal side to lift the round ligament.

The cystic artery was identified crossing in front of the

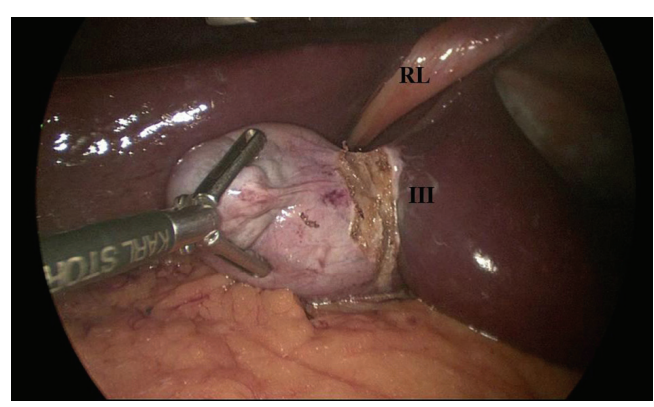

Figure 1. RL: round ligament; III: segment 3 of the liver. 


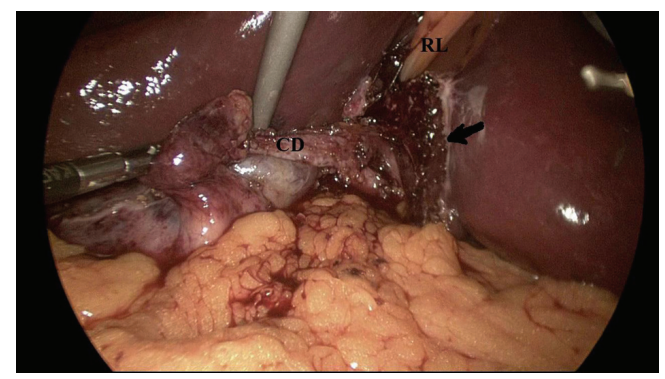

Figure 2. CD: cystic duct; RL: round ligament; Arrow: Gallbladder bed on the surface of segment 3 and to the left of round ligament.

CBD, clipped with titanium clips and cut. Because of it was difficult to expose and open Calot's triangle we decided to perform an anterograde dissection of gallbladder from the fundus towards infundibulum. When only cystic duct remained (Fig. 2), it was clipped and cut and the procedure was concluded. A drain was left in surgical site.

In the first postoperative day there was a biliary leak from drainage tube with maximum daily output of $150 \mathrm{~mL}$. No fever or sepsis signs were present. An abdominal ultrasound scan showed no peritoneal fluid. The biliary leak stopped in third postoperative day. Another abdominal ultrasound scan was performed and it showed no peritoneal fluid and the patient was discharge in fifth postoperative day. She is asymptomatic at the 3-month follow-up.

\section{Discussion}

Malposition of gallbladder occurring in the absence of situs inversus is a very rare anomaly and its incidence is estimated to be between $0.1 \%$ and $1.2 \%$. Two anatomic variants of gallbladder malposition are described [4]: medioposition and sinistroposition. In medioposition (Fig. 3), the gallbladder is displaced medially to the base of the quadrate lobe (segment 4) but remains to the right of the round ligament. In sinistro-

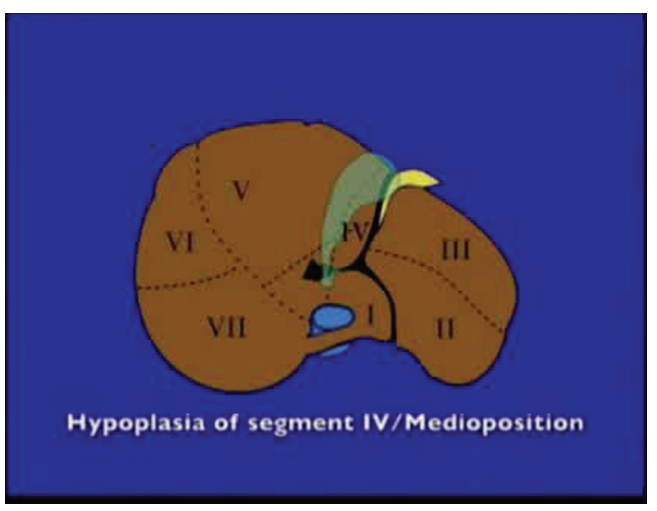

Figure 3. Medioposition (from Skandalakis JE et al [5]).

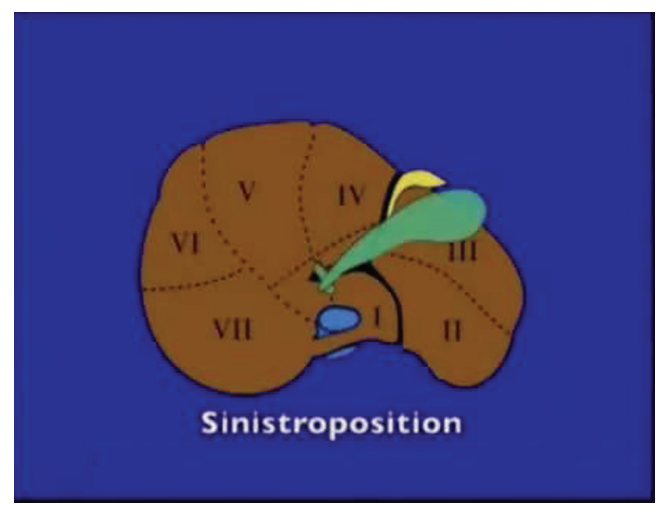

Figure 4. Sinistroposition (true left-sided gallbladder) (from Skandalakis JE et al [5]).

position (Fig. 4), the gallbladder is located at the base of segment 3 to the left of the round ligament. This variant is a true left-sided gallbladder in which the cystic artery, as in our reported case, always crosses in front of the CBD from right to left. The cystic duct may join the right side of the CBD crossing in front of it from left to right (Fig. 5a) or may join the left side (Fig. 5c) or the left hepatic duct directly (Fig. $5 b)$. Of 41 patients with LSG, Nagai et al [1] found 20 with the cystic duct joining the CBD from the right side and 11 from the left. In 2 patients, the CBD directly joined the right hepatic duct and in one patient the left hepatic duct. Because of routine preoperative ultrasonography may fail to identify LSG, surgeons encountering incidental left-sided gallbladder should be aware of the possibility of associated anomalies particularly in the way the cystic duct joins the biliary tree to avoid injuries to the bile ducts. For these reasons we recommend to initiate the dissection carefully and as close to the gallbladder as possible. When the preparation of the elements of Calot's triangle is difficult or when the anatomy appairs unclear, an anterograde approach starting the dissection of gallbladder from the fundus represent a valid and sure method. This technique allows to mobilize and rotate to the right the gallbladder, exposing the cystic duct junction with the CBD, increasing the safety of the operation. Particular attention should be paid to the posterior aspect of the dissection of the gallbladder bed as it crosses, from left to right, just anterior to the common hepatic duct and porta hepatis in order to avoid potential major complications.

\section{Conflict of Interest}

None.

\section{Grant Support}

None. 

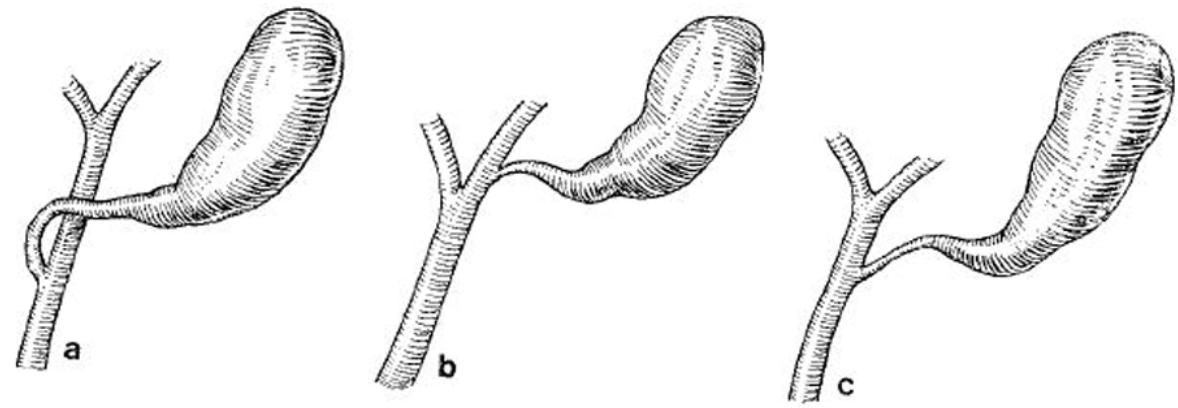

Figure 5. More frequent kinds of cystic duct junction with the CBD.

\section{References}

1. Nagai M, Kubota K, Kawasaki S, Takayama T, BandaiY, Makuuchi M. Are left-sided gallbladders really located on the left side? Ann Surg. 1997;225(3):274-280.

2. Hochstetter F. Anomalien der Pfortader und der Nabelvene in Verbindung mit Defect oder Linkslage der Gallenblase. Arch Anat Entwick 1886; 369-384.
3. Bittner R. The standard of laparoscopic cholecystectomy. Langenbecks Arch Surg. 2004;389(3):157-163.

4. Hsu SL, Chen TY, Huang TL, Sun CK, Concejero AM, Tsang LL, Cheng YF. Left-sided gallbladder: its clinical significance and imaging presentations. World J Gastroenterol. 2007;13(47):6404-6409.

5. Skandalakis JE, Skandalakis LJ, Skandalakis PN, Mirilas P. Hepatic surgical anatomy. Surg Clin North Am. 2004;84(2):413-435, viii. 